\title{
Impact of HIV Infection on Medicare Beneficiaries with Lung Cancer
}

\author{
Jeannette Y. Lee, Page C. Moore, and Shelly Y. Lensing \\ Department of Biostatistics, University of Arkansas for Medical Sciences, 4301 West Markham, No. 781, Little Rock, \\ AR 72205, USA \\ Correspondence should be addressed to Jeannette Y. Lee, jylee@uams.edu
}

Received 19 October 2011; Revised 17 January 2012; Accepted 26 January 2012

Academic Editor: Jennifer Beebe-Dimmer

Copyright ( $\odot 2012$ Jeannette Y. Lee et al. This is an open access article distributed under the Creative Commons Attribution License, which permits unrestricted use, distribution, and reproduction in any medium, provided the original work is properly cited.

\begin{abstract}
The incidence of lung cancer among individuals infected with the human immunodeficiency virus (HIV) is elevated compared to that among the general population. This study examines the prevalence of HIV and its impact on outcomes among Medicare beneficiaries who are 65 years of age or older and were diagnosed with nonsmall cell lung cancer (NSCLC) between 1997 and 2008. Prevalence of HIV was estimated using the Poisson point estimate and its 95\% confidence interval. Relative risks for potential risk factors were estimated using the log-binomial model. A total of 111,219 Medicare beneficiaries met the study criteria. The prevalence of HIV was 156.4 per 100,000 (95\% CI: 140.8 to 173.8 ) and has increased with time. Stage at NSCLC diagnosis did not vary by HIV status. Mortality rates due to all causes were $44 \%, 76 \%$, and $88 \%$ for patients with stage I/II, III, and IV NSCLC, respectively. Across stages of disease, there was no difference between those who were HIV-infected and those who were not with respect to overall mortality. HIV patients, however, were more likely to die of causes other than lung cancer than their immunocompetent counterparts.
\end{abstract}

\section{Introduction}

With the widespread use of highly active antiretroviral therapy (HAART), the incidence of non-AIDS defining malignancies among HIV-infected persons has increased $[1,2]$. The most frequently reported non-AIDS defining cancer among HIV-infected individuals is lung cancer. The incidence of lung cancer among individuals infected with human immunodeficiency virus (HIV) is elevated compared to the incidence in the general population [1-8] and has increased with time [2]. HIV-infected individuals are at least twice as likely as those who are not infected with HIV to be diagnosed with lung cancer $[1,6,8]$. The risk of lung cancer among HIV-infected patients is inversely related to CD4 count, a measure of immune function [9], and it has been suggested that use of antiretroviral viral therapy may reduce the risk of lung cancer [10]. At the time of lung cancer diagnosis, HIV-infected patients were younger than those who were not shown to have HIV $[11,12]$.
Survival of HIV-infected lung cancer patients was similar to that of their immunocompetent counterparts when the majority of HIV-infected patients were on HAART $[11,13]$. Positive prognostic factors for survival among HIV-infected lung cancer cases are the use of HAART [14] and CD4 counts [15]. The impact of HIV infection on the population of lung cancer patients is unclear. This study uses data from the SEER-Medicare database to determine the prevalence of HIV infection among Medicare beneficiaries with nonsmall cell lung cancer (NSCLC) and its implications for their outcomes.

\section{Materials and Methods}

The basis for this study was the SEER-Medicare database which links Medicare claims data with patients identified through cancer registries as part of the Surveillance Epidemiology and End Results (SEERs) program (http://www.seer.cancer.gov/). The SEER database includes 
information on patient demographic characteristics, primary tumor site, histology and stage of disease at diagnosis, initial course of treatment, and follow-up vital status from population-based registries in the USA.

This study includes patients who were diagnosed with nonsmall cell lung cancer between 1998 and 2007 as their first cancer, were not diagnosed at autopsy or by death certificate, were staged using the American Joint Commission on Cancer (AJCC) staging system [16], were covered by Medicare Parts A and B continuously for 6 months preceding lung cancer diagnosis and 2 months after diagnosis, qualified for Medicare based on age, and were 65 years of age or older at the time of the lung cancer diagnosis. Medicare Parts A and B cover hospitalization and outpatient services, respectively. Patients who qualified for Medicare based on disability, endstage renal disease alone, or for whom the basis of Medicare qualification was unknown were excluded from all analyses. A total of 111,219 Medicare beneficiaries met these criteria.

HIV patients were identified based on the International Classification of Diseases, version 9, "042" diagnosis reported in the databases of Medicare claims for health care services given between 1998 and 2009. The Medicare claims databases were Medicare Provider Analysis and Review (MEDPAR), Carrier Claims (NCH), Outpatient Claims (OUTPT), and Home Health Agency (HHA). Prevalent cases of HIV were defined as cases whose first Medicare claim with an HIV diagnosis either preceded the diagnosis of lung cancer or occurred within 90 days after lung cancer diagnosis.

Age at diagnosis was categorized in 5-year intervals (65$69,70-74,75-84,85+)$. For purposes of this study, they were further grouped into 3 age groups: $65-74,75-84$, and 85 years of age and older. The areas of residence for patients were classified as Big Metro (residing in counties with populations in excess of 1 million), Metro (residing in counties with populations between 250,000 and 1 million), or Other (residing in counties with populations below 250,000).

Prevalence of HIV was estimated assuming its point estimate and 95\% Poisson confidence intervals. Relative risks (RR) and their 95\% confidence intervals were estimated using the log-binomial regression model [17]. Pearson's chisquare test and Fisher's exact test were used to compare HIV and non-HIV lung cancer patients with respect to demographic characteristics. The Cochran-Armitage trend test was used to evaluate trends in prevalence of HIV over time. The Cochran-Mantel-Haenszel test was used to compare HIV and non-HIV groups with respect to the mortality rates across stages of disease. The log-binomial regression model [17] was used to evaluate the association between mortality due to all causes and lung cancer with demographic factors, stage of disease and HIV status, and their relative risks.

\section{Results}

A total of 174 NSCLC cases had an HIV diagnosis. The demographic profile among HIV patients differed from that of their HIV negative counterparts (Table 1). NSCLC patients infected with HIV were more likely to be men, from a
TABLE 1: Demographic characteristics of NSCLC cases based on HIV infection status.

\begin{tabular}{|c|c|c|}
\hline & $\operatorname{HIV}(N=174)$ & $\begin{array}{c}\text { Non-HIV } \\
(N=111,045)\end{array}$ \\
\hline \multirow[t]{2}{*}{ Men (\%) } & 67.8 & 52.4 \\
\hline & \multicolumn{2}{|c|}{$P<0.001^{*}$} \\
\hline \multicolumn{3}{|l|}{ Age, years (\%) } \\
\hline $65-74$ & 60.9 & 50.0 \\
\hline $75-84$ & 35.6 & 41.9 \\
\hline \multirow[t]{2}{*}{$85+$} & 3.5 & 8.1 \\
\hline & \multicolumn{2}{|c|}{$P=0.005^{*}$} \\
\hline \multicolumn{3}{|l|}{ Race (\%) } \\
\hline White & 58.6 & 86.7 \\
\hline Black & 34.2 & 7.9 \\
\hline \multirow[t]{2}{*}{ Other } & 7.2 & 5.4 \\
\hline & \multicolumn{2}{|c|}{$P<0.001^{*}$} \\
\hline \multicolumn{3}{|l|}{ Never married (\%) } \\
\hline \multirow[t]{2}{*}{ Men } & 33.1 & 7.5 \\
\hline & \multicolumn{2}{|c|}{$P<0.001^{*}$} \\
\hline \multirow[t]{2}{*}{ Women } & 5.4 & 6.6 \\
\hline & \multicolumn{2}{|c|}{$P=0.717^{*}$} \\
\hline \multirow[t]{2}{*}{ Both } & 24.1 & 7.0 \\
\hline & \multicolumn{2}{|c|}{$P<0.001^{*}$} \\
\hline \multicolumn{3}{|l|}{ Urban/Rural (\%) } \\
\hline Big Metro & 81.6 & 61.2 \\
\hline Metro & 17.2 & 25.9 \\
\hline \multirow[t]{2}{*}{ Other } & 1.2 & 12.9 \\
\hline & \multicolumn{2}{|c|}{$P<0.001^{*}$} \\
\hline \multicolumn{3}{|l|}{ Stage of disease } \\
\hline I & 30.5 & 26.3 \\
\hline II & 2.3 & 2.8 \\
\hline III & 31.6 & 31.8 \\
\hline \multirow[t]{2}{*}{ IV } & 35.6 & 39.1 \\
\hline & \multicolumn{2}{|c|}{$P=0.064^{*}$} \\
\hline \multicolumn{3}{|l|}{ Histology } \\
\hline Large cell carcinoma & 5.8 & 4.4 \\
\hline $\begin{array}{l}\text { Squamous cell } \\
\text { carcinoma }\end{array}$ & 24.1 & 25.4 \\
\hline Adenocarcinoma & 35.1 & 35.4 \\
\hline \multirow[t]{2}{*}{ Other, unspecified } & 35.1 & 34.8 \\
\hline & \multicolumn{2}{|c|}{$P=0.847^{*}$} \\
\hline
\end{tabular}

${ }^{*}$ For comparing HIV and non-HIV patients.

minority group, not currently or previously married, residents of a large metropolitan area, and younger than their non-HIV counterparts. Among HIV-infected NSCLC patients, over $40 \%$ were from a minority population in comparison to $13 \%$ of those who were not HIV-infected. Individuals who were 75 years or older at diagnosis comprised half of the non-HIV and only $39 \%$ of the HIV-infected NSCLC patients. There were no significant differences between HIV and non-HIV patients with respect to stage of disease 
TAble 2: Prevalence of HIV among Medicare Beneficiaries 65 years of age and older who qualified based on age.

\begin{tabular}{|c|c|c|c|c|c|}
\hline & Non-HIV $(N)$ & $\operatorname{HIV}(N)$ & $\begin{array}{l}\text { Prevalence per } 100,000 \\
(95 \% \mathrm{CI})\end{array}$ & Relative risk (95\% CI) & $P$ value \\
\hline \multicolumn{6}{|l|}{ Gender } \\
\hline Male & 58,211 & 118 & $202.3(168.9,242.3)$ & $1.91(1.39,2.63)$ & $<0.001$ \\
\hline Female & 52,834 & 56 & $105.9(81.5,137.6)$ & Reference & \\
\hline \multicolumn{6}{|l|}{ Race } \\
\hline White & 96,437 & 102 & $105.7(87.0,128.3)$ & Reference & \\
\hline Black & 8,771 & 64 & $724.4(567.0,925.5)$ & $6.86(5.02,9.36)$ & $<0.001$ \\
\hline Other & 5,837 & 8 & $136.9(68.4,273.7)$ & $1.30(0.63,2.66)$ & 0.480 \\
\hline \multicolumn{6}{|l|}{ Age, years } \\
\hline $65-74$ & 55,491 & 106 & $190.7(157.6,230.6)$ & Reference & \\
\hline $75-84$ & 46,585 & 62 & $132.9(103.6,170.5)$ & $0.70(0.51,0.95)$ & 0.024 \\
\hline $85+$ & 8,969 & 6 & $66.9(30.0,148.8)$ & $0.35(0.15,0.80)$ & 0.012 \\
\hline \multicolumn{6}{|c|}{ Marital status_-Men } \\
\hline Never married & 4,346 & 39 & $889.4(649.8,1217.3)$ & $6.07(4.14,8.90)$ & $<0.001$ \\
\hline Other & 53,865 & 79 & $146.4(117.5,182.6)$ & Reference & \\
\hline \multicolumn{6}{|c|}{ Marital status-Women } \\
\hline Never married & 3,465 & 3 & $86.5(27.9,268.2)$ & $0.81(0.25,2.58)$ & 0.717 \\
\hline Other & 49,369 & 53 & $107.2(81.9,140.4)$ & Reference & \\
\hline \multicolumn{6}{|c|}{ Urban/Rural Residence } \\
\hline Big Metro & 67,937 & 142 & $208.6(176.9,245.9)$ & Reference & \\
\hline Metro & 28,725 & 30 & $104.3(72.9,149.2)$ & $0.50(0.34,0.74)$ & $<0.001$ \\
\hline Other & 14,383 & 2 & $13.9(3.5,55.6)$ & $0.07(0.02,0.27)$ & $<0.001$ \\
\hline
\end{tabular}

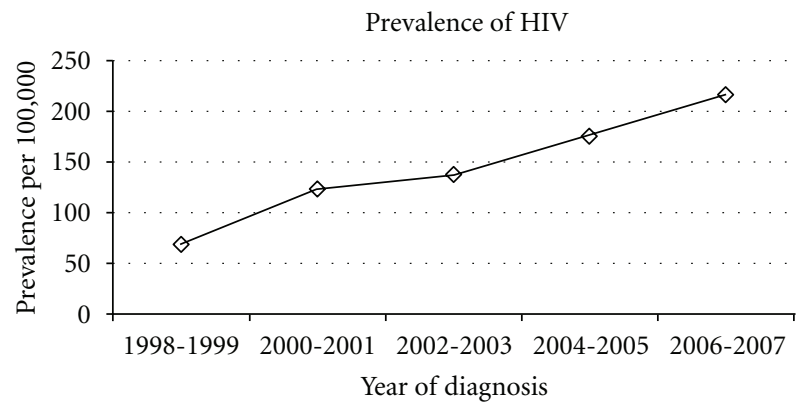

Figure 1: Prevalence of HIV over time among Medicare beneficiaries diagnosed with nonsmall cell lung cancer from the SEERMedicare database.

$(P=0.604)$ or histologic type $(P=0.847)$ at the time of NSCLC diagnosis.

The prevalence of HIV was 156.4 per 100,000 (95\% CI: 140.8 to 173.8 ) among Medicare beneficiaries. Men were almost twice as likely to be HIV-infected than women (Table 2) and African-Americans were 6.9 times as likely to be HIV-infected than white beneficiaries. Prevalence of HIV declined with age. Men who had never been married were 6 times more likely to have HIV than their currently or previously married counterparts. For women, remaining single was not associated with an increased risk of HIV. From 1998 to 2007, the prevalence of HIV tripled from 69.1 to 216.6 per $100,000(P<0.001)$ (Figure 1$)$.

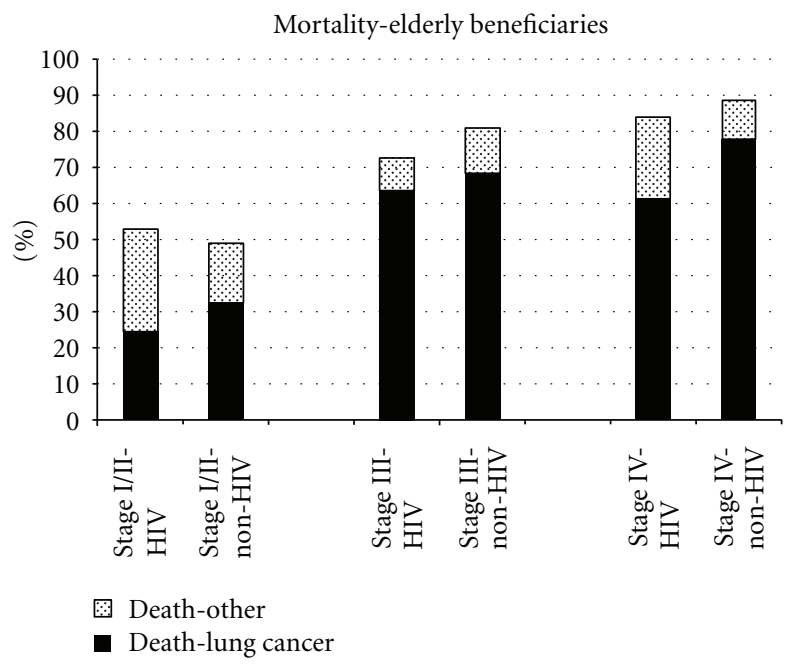

FIGURE 2: Mortality rate by stage of disease, HIV status, and cause from the SEER-Medicare database.

Mortality rates due to all causes were $44 \%, 76 \%$, and $88 \%$ for patients with stages I/II, III, and IV NSCLC, respectively, and did not vary with HIV status $(P=0.320)$ (Figure 2). HIV-infected patients were less likely to die of lung cancer than those who were not infected with HIV $(P=0.004)$. Death due to HIV was reported for $2.9 \%$ HIV-infected patients and none of non-HIV patients. In 
TABLE 3: Relative Risk (RR) for all causes mortality and lung cancer mortality.

\begin{tabular}{|c|c|c|c|c|}
\hline & \multicolumn{2}{|c|}{ Mortality due to any cause } & \multicolumn{2}{|c|}{ Mortality due to lung cancer } \\
\hline & Relative risk (95\% CI) & $P$ value & Relative risk (95\% CI) & $P$ value \\
\hline Stage III versus I/II & $1.66(1.64,1.68)$ & $<0.001$ & $2.11(2.08,2.15)$ & $<0.001$ \\
\hline Stage IV versus I/II & $1.80(1.78,1.82)$ & $<0.001$ & $2.40(2.36,2.44)$ & $<0.001$ \\
\hline Male versus female & $1.05(1.04,1.05)$ & $<0.001$ & $1.05(1.04,1.06)$ & $<0.001$ \\
\hline Black versus white & $1.02(1.01,1.03)$ & $<0.001$ & $0.99(0.98,1.01)$ & 0.472 \\
\hline Other versus white & $0.96(0.94,0.97)$ & $<0.001$ & $0.94(0.92,0.96)$ & $<0.001$ \\
\hline Age $75-84$ versus $65-74$ & $1.04(1.03,1.05)$ & $<0.001$ & $1.02(1.01,1.03)$ & $<0.001$ \\
\hline Age $85+$ versus $65-74$ & $1.07(1.06,1.08)$ & $<0.001$ & $1.02(1.01,1.03)$ & 0.008 \\
\hline Metro versus Big Metro & $1.00(1.00,1.01)$ & 0.569 & $1.00(0.99,1.01)$ & 0.458 \\
\hline Other versus Big Metro & $1.01(1.00,1.02)$ & 0.066 & $1.01(1.00,1.02)$ & 0.088 \\
\hline Single versus Other & $1.00(0.99,1.01)$ & 0.079 & $0.99(0.97,1.01)$ & 0.076 \\
\hline HIV versus non-HIV & $0.94(0.86,1.02)$ & 0.132 & $0.84(0.73,0.96)$ & 0.011 \\
\hline
\end{tabular}

a multivariate analysis, stage of disease, gender, age, and race were associated with mortality due to all causes and due to lung cancer (Table 3). HIV infection was not significantly associated with mortality due to all causes but was negatively associated with lung cancer mortality.

\section{Discussion}

In comparison to HIV-infected Medicare beneficiaries without cancer, the HIV-infected lung cancer cases in our study were older, but similar with respect to gender and racial distributions [18]. The larger proportion of men and minorities among the HIV-infected lung cancer cases reflects the population characteristics of HIV infection in the USA [19]. The finding that African-Americans and men are overrepresented in the HIV positive lung cancer cases can be attributed to their higher prevalence of HIV in the population overall [19] and the higher incidence of lung cancer for African-American men as compared to white men [20]. One-third of the HIV-infected men had never been married, 4 times the proportion among the nonHIV Medicare beneficiaries, which suggests that a sizable proportion of the HIV-infected Medicare lung cancer cases may be among men who have sex with men (MSM).

The overall prevalence of HIV among elderly Medicare beneficiaries diagnosed with NSCLC of 156.4 per 100,000 is 1.6 times greater than the rate of persons living with HIV among those 65 years of age or older in the USA in 2008 [21]. Higher prevalence rates for documented HIV infection among persons 65 years of age and older were reported in a study of Veterans Affairs health systems [22]. HIV prevalence rates in this study are higher than those reported among elderly Medicare beneficiaries by Gilden et al. [18]; however, that study used a more stringent criteria for defining HIV patients [18]. The disparity in HIV prevalence based on race and gender among the Medicare NSCLC patients was similar to that in the general population where blacks are 8 times more likely to be infected with HIV than whites, and men were 3 times more likely than women to be HIV-infected [21].
The prevalence of HIV among men with NSCLC who were currently or previously married is slightly lower than the reported prevalence of HIV among adult men under 60 years of age who are not MSM $[23,24]$. In this study, single men who had never married were 6 times more likely to have HIV than those who had been married. Younger MSM are 36 times more likely to be HIV-infected than other men [23]. The smaller disparity in this study may be due to the older age of the NSCLC cases and the possibility that a proportion of men who had never married are not MSM. The finding that the prevalence of HIV was higher for NSCLC patients that resided in large metropolitan areas is consistent with the urban-rural distribution of HIV in the USA. The rate of persons living with a diagnosis of HIV infection is twice as high in metropolitan areas of 500,000 residents or more than in smaller areas [25].

The younger age at lung cancer diagnosis for the HIV patients has been previously reported $[11,12]$. It is not known whether this represents earlier exposure to known risk factors such as smoking and tobacco use or the independent effect of HIV infection [26, 27]. In comparison to the general population where $23.5 \%$ of men and $17.9 \%$ of women report that they are current cigarette smokers $[26,28]$, it has been reported that over $40 \%$ of HIVinfected individuals are cigarette smokers [29, 30]. The higher rate of smoking has been linked to an increased risk of morbidity for HIV-infected persons from non-AIDS-related cancers (including lung cancer), cardiovascular disease, and pneumonia [29].

The finding that stage of lung cancer at the time of diagnosis did not differ between HIV and non-HIV infected beneficiaries is correlated with reports that the elevated risk of lung cancer for HIV-infected individuals does not vary by stage of disease [12]. Since $94 \%$ of those 65 years of age or older have Medicare coverage [31], the comparable distribution of stages may reflect the fact that, in this age group, HIV-infected patients have access to health care similar to that of immunocompetent patients.

The increasing prevalence of HIV over time among elderly Medicare beneficiaries with lung cancer reflects 
the temporal increase in rate of persons living with HIV [32]. Recently, the prevalence of HIV among those 65 years of age or older has risen from 51.1 per 100,000 in 2005 [32] to 99.0 per 100,000 in 2008 [21]. Since the overall HIV incidence has not increased $[33,34]$, much of the increase in HIV prevalence may be attributed to effect of highly active antiretroviral therapy in extending survival which places some HIV patients at risk for chronic diseases of the aging.

The finding that HIV infection did not have an impact on overall survival of lung cancer patients confirms other reports $[11,13]$ and suggests that HIV and lung cancer serve as competing risks for this population. The lower mortality due to lung cancer among HIV patients can be attributed to their mortality due to HIV-related causes.

There are a number of limitations to this study. The issues related to generalization from the SEER population to the US population as a whole have been previously described [35]. In comparison to the US population as a whole, the SEER population is more affluent, more highly educated, and more urban [35]. The SEER-Medicare-linked database does not contain information on risk factors for lung cancer such as tobacco use or occupational exposure, nor does it provide measures of severity of HIV infection such as HIV load or CD4 counts. Similarly, the mechanism of HIV acquisition is not captured as part of the database. Identification of the HIV cases was based on diagnostic codes provided on Medicare claims data, not HIV serology. Marital status was used as an indicator of sexual orientation among men since this information was not collected in the database.

\section{Conclusion}

This paper demonstrates that the prevalence of HIV infection among NSCLC patients over 65 years of age is growing with time. The risk factors associated with HIV infection in older NSCLC patients reflect those in the general population. HIV infection is not associated with an increase in overall mortality among NSCLC patients but serves as a competing risk with lung cancer so that HIV-infected individuals have a lower mortality due to lung cancer.

\section{Acknowledgments}

This work was supported by an award from the University of Arkansas for Medical Sciences Medical Research Endowment and NIH Grant 1ULRR029884.

\section{References}

[1] E. A. Engels, R. J. Biggar, H. I. Hall et al., "Cancer risk in people infected with human immunodeficiency virus in the United States," International Journal of Cancer, vol. 123, no. 1, pp. 187-194, 2008.

[2] M. S. Shiels, R. M. Pfeiffer, M. H. Gail et al., "Cancer burden in the HIV-infected population in the United States," Journal of the National Cancer Institute, vol. 103, no. 9, pp. 753-762, 2011.

[3] P. Patel, D. L. Hanson, P. S. Sullivan et al., "Incidence of types of cancer among HIV-infected persons compared with the general population in the United States, 1992-2003," Annals of Internal Medicine, vol. 148, no. 10, pp. 728-736, 2008.

[4] L. Pantanowitz, H. P. Schlecht, and B. J. Dezube, "The growing problem of non-AIDS-defining malignancies in HIV," Current Opinion in Oncology, vol. 18, no. 5, pp. 469-478, 2006.

[5] E. P. Simard, R. M. Pfeiffer, and E. A. Engels, "Cumulative incidence of cancer among individuals with acquired immunodeficiency syndrome in the United States," Cancer, vol. 117, no. 5, pp. 1089-1096, 2011.

[6] M. S. Shiels, S. R. Cole, G. D. Kirk, and C. Poole, "A metaanalysis of the incidence of non-AIDS cancers in HIVinfected individuals," Journal of Acquired Immune Deficiency Syndromes, vol. 52, no. 5, pp. 611-622, 2009.

[7] M. J. Silverberg, C. Chao, W. A. Leyden et al., "HIV infection and the risk of cancers with and without a known infectious cause," AIDS, vol. 23, no. 17, pp. 2337-2345, 2009.

[8] N. A. Hessol, E. C. Seaberg, S. Preston-Martin et al., "Cancer risk among participants in the women's interagency HIV study," Journal of Acquired Immune Deficiency Syndromes, vol. 36, no. 4, pp. 978-985, 2004.

[9] J. Reekie, C. Kosa, F. Engsig et al., "Relationship between current level of immunodeficiency and non-acquired immunodeficiency syndrome-defining malignancies," Cancer, vol. 116, no. 22, pp. 5306-5315, 2010.

[10] M. J. Silverberg and D. I. Abrams, "Do antiretrovirals reduce the risk of non-AIDS-defining malignancies?" Current Opinion in HIV and AIDS, vol. 4, no. 1, pp. 42-51, 2009.

[11] G. D’Jaen, L. Pantanowitz, M. Bower et al., "Human immunodeficiency virus-associated primary lung cancer in the era of highly active antiretroviral therapy: a multi-institutional collaboration," Clinical Lung Cancer, vol. 11, no. 6, pp. 396404, 2010.

[12] M. S. Shiels, R. M. Pfeiffer, and E. A. Engels, "Age at cancer diagnosis among persons with AIDS in the United States," Annals of Internal Medicine, vol. 153, no. 7, pp. 452-460, 2010.

[13] T. Powles, C. Thirwell, T. Newsom-Davis et al., "Does HIV adversely influence the outcome in advanced non-small-cell lung cancer in the era of HAART?" British Journal of Cancer, vol. 89, no. 3, pp. 457-459, 2003.

[14] A. Lavolé, C. Chouaïd, L. Baudrin et al., "Effect of highly active antiretroviral therapy on survival of HIV infected patients with non-small-cell lung cancer," Lung Cancer, vol. 65, no. 3, pp. 345-350, 2009.

[15] A. Makinson, J.-C. Tenon, S. Eymard-Duvernay et al., "Human immunodeficiency virus infection and non-small cell lung cancer: survival and toxicity of antineoplastic chemotherapy in a cohort study," Journal of Thoracic Oncology, vol. 6, no. 6, pp. 1022-1029, 2011.

[16] O. Beahrs, D. Henson, R. Hutter et al., AJCC Cancer Stating Manual, New York, NY, USA, J. B. Lippincott Company, 3rd edition, 1988.

[17] D. Spiegelman and E. Hertzmark, "Easy SAS calculations for risk or prevalence ratios and differences," American Journal of Epidemiology, vol. 162, no. 3, pp. 199-200, 2005.

[18] D. E. Gilden, J. M. Kubisiak, and D. M. Gilden, "Managing Medicare's HIV caseload in the era of suppressive therapy," American Journal of Public Health, vol. 97, no. 6, pp. 10531059, 2007.

[19] HIV/AIDS Surveillance Report, Centers for Disease Control and Prevention, U.S. Department of Health and Human Services, Atlanta, Ga, USA, 2007.

[20] American Cancer Society, Cancer Facts \& Figures 2011, Atlanta, Ga, USA, 2011. 
[21] "HIV surveillance-United States, 1981-2008," Morbidity and Mortality Weekly Report, vol. 60, no. 21, pp. 689-693, 2011.

[22] D. K. Owens, V. Sundaram, L. C. Lazzeroni et al., "Prevalence of HIV infection among inpatients and outpatients in department of veterans affairs health care systems: implications for screening programs for HIV," American Journal of Public Health, vol. 97, no. 12, pp. 2173-2178, 2007.

[23] S. Lieb, J. Prejean, D. R. Thompson et al., "HIV prevalence rates among men who have sex with men in the southern united states: population-based estimates by race/ethnicity," AIDS and Behavior, vol. 15, no. 3, pp. 596-606, 2011.

[24] F. Xu, M. R. Sternberg, and L. E. Markowitz, "Men who have sex with men in the united states: demographic and behavioral characteristics and prevalence of hiv and hsv-2 infection: results from national health and nutrition examination survey 2001-2006," Sexually Transmitted Diseases, vol. 37, no. 6, pp. 399-405, 2010.

[25] HIV Surveillance in Urban and Nonurban Areas, Centers for Disease Control and Prevention, National Center for HIV/ AIDS, Viral Hepatitis, STD \& TB Prevention, Division of HIV/AIDS Prevention, 2010, http://www.cdc.gov/hiv/topics/ surveillance/resources/slides/urban-nonurban/index.htm.

[26] E. A. Engels, M. V. Brock, J. Chen, C. M. Hooker, M. Gillison, and R. D. Moore, "Elevated incidence of lung cancer among HIV-infected individuals," Journal of Clinical Oncology, vol. 24, no. 9, pp. 1383-1388, 2006.

[27] G. D. Kirk, C. Merlo, P. O'Driscoll et al., "HIV infection is associated with an increased risk for lung cancer, independent of smoking," Clinical Infectious Diseases, vol. 45, no. 1, pp. 103 110, 2007.

[28] "Vital signs: current cigarette smoking among adults aged $\geq 18$ years-United States, 2009," Morbidity and Mortality Weekly Report, vol. 59, no. 35, pp. 1135-1140, 2010.

[29] A. R. Lifson, J. Neuhaus, J. R. Arribas, M. D. van Berg-Wolf, A. M. Labriola, and T. R. H. Read, "Smoking-related health risks among persons with HIV in the strategies for management of antiretroviral therapy clinical trial," American Journal of Public Health, vol. 100, no. 10, pp. 1896-1903, 2010.

[30] H. Pines, L. Koutsky, and S. Buskin, "Cigarette smoking and mortality among HIV-infected individuals in Seattle, Washington (1996-2008)," AIDS and Behavior, vol. 15, no. 1, pp. 243-251, 2011.

[31] Centers for Disease Control and Prevention, National Center for Health Statistics, National Interview Survey, 2010, Family Core Component, 2011.

[32] HIV/AIDS Surveillance Report, Centers for Disease Control and Prevention, U.S. Department of Health and Human Services, Atlanta, Ga, USA, 2008.

[33] H. I. Hall, R. Song, P. Rhodes et al., "Estimation of HIV incidence in the United States," Journal of the American Medical Association, vol. 300, no. 5, pp. 520-529, 2008.

[34] S. Zou, K. A. Dorsey, E. P. Notari et al., "Prevalence, incidence, and residual risk of human immunodeficiency virus and hepatitis $\mathrm{C}$ virus infections among United States blood donors since the introduction of nucleic acid testing," Transfusion, vol. 50, no. 7, pp. 1495-1504, 2010.

[35] A. B. Nattinger, T. L. McAuliffe, and M. M. Schapira, "Generalizability of the surveillance, epidemiology, and end results registry population: factors relevant to epidemiologic and health care research," Journal of Clinical Epidemiology, vol. 50, no. 8, pp. 939-945, 1997. 


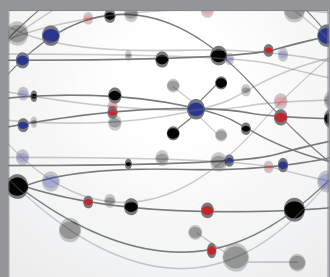

The Scientific World Journal
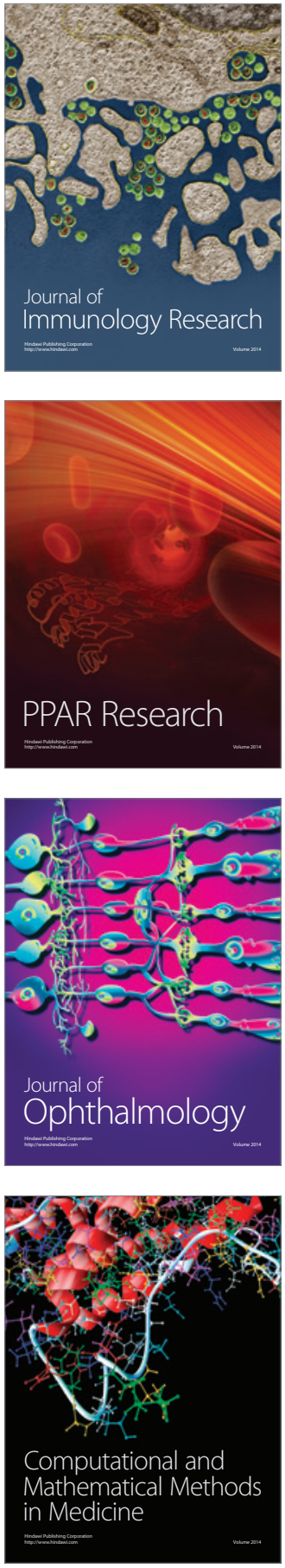

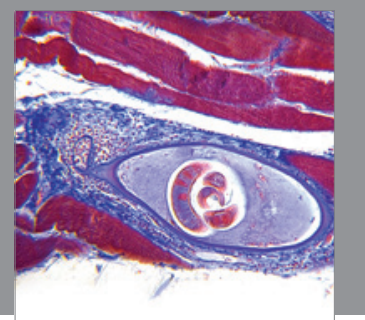

Gastroenterology

Research and Practice
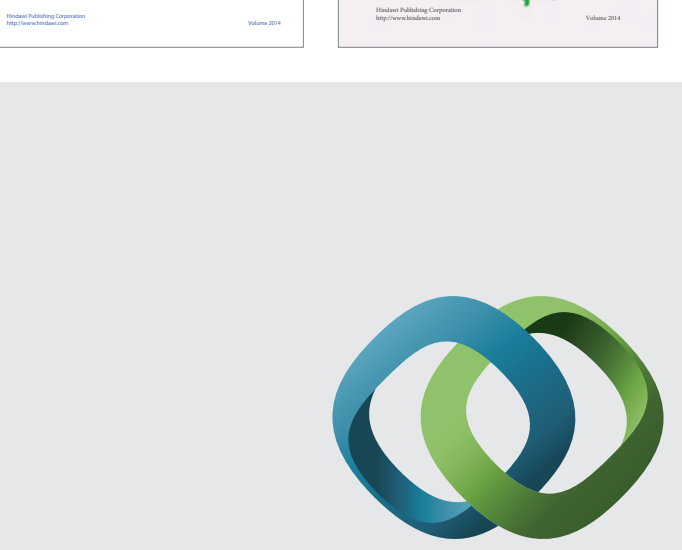

\section{Hindawi}

Submit your manuscripts at

http://www.hindawi.com
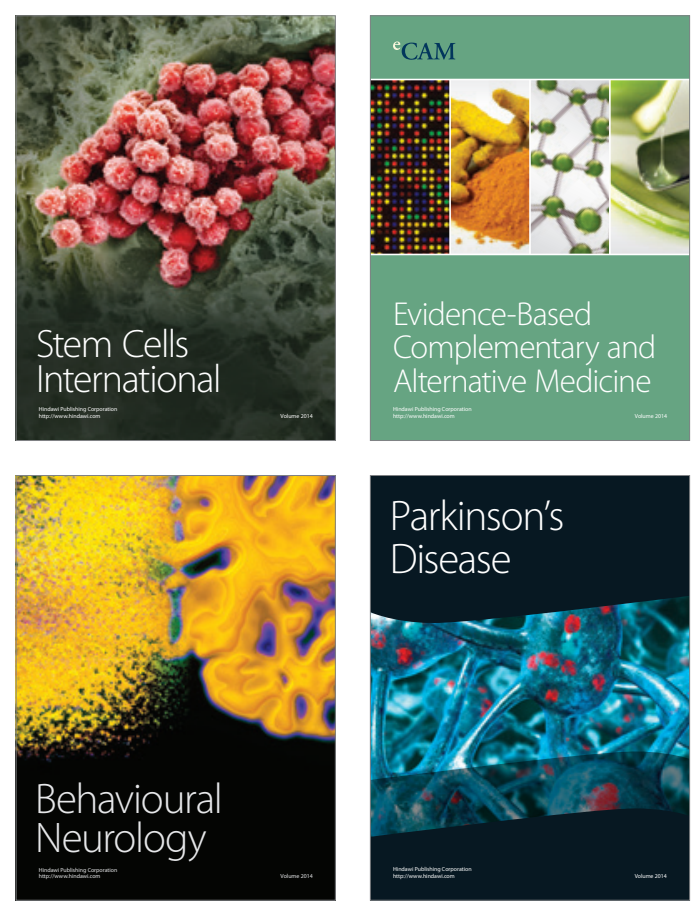

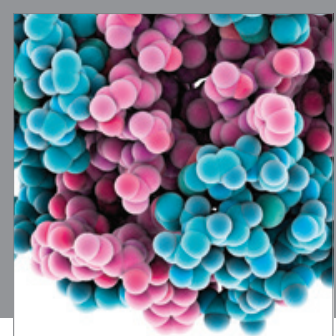

Journal of
Diabetes Research

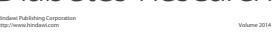

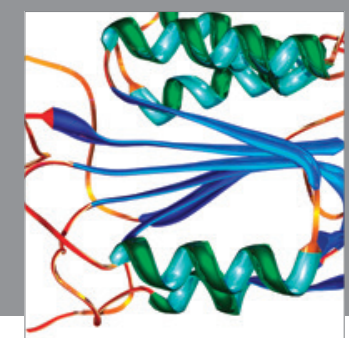

Disease Markers
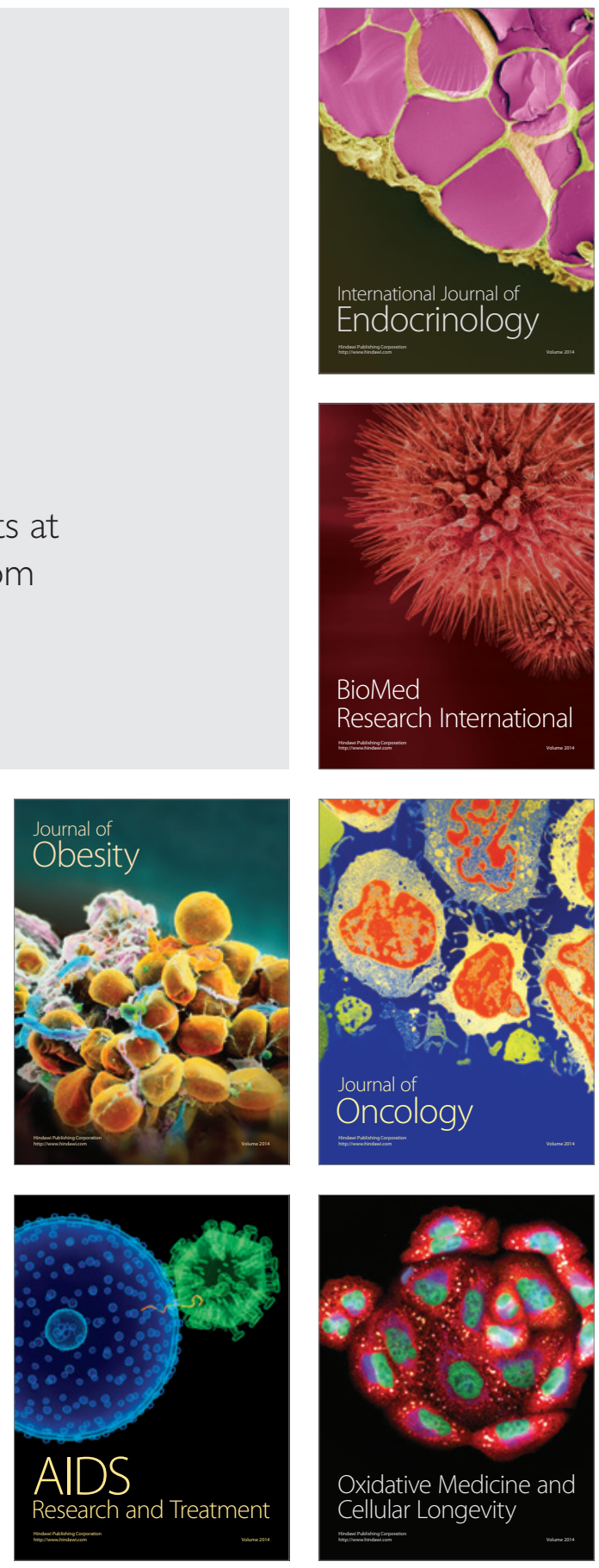